\title{
Black gold causes a stir
}

\section{London}

A SwEDISH drilling company claims to have discovered crude oil in a granite rock formation - a location that should not contain oil, according to the currently accepted theory of oil formation, which holds that oil and natural gas are formed from biological material buried in sediments.

If the new finding is confirmed, it will lend some support to a controversial theory proposed by Thomas Gold from Cornell University. Gold argues that gas and oil deposits originate from methane, released from deep within the Earth, which has seeped up into sediments near the surface. He says he has no doubt that the new find supports his theory: "The case to me is completely clear."

The challenge to orthodox petroleum geology was met with scepticism last week by geologists and geochemists alike. Many said they would want more evidence that the oil could not have originated from sedimentary rocks in the surrounding area before they could accept the find at face value.

The Swedish claim was made on 8 October by Dala Djupgas Produktions, which is drilling deep into the granite rock below the centre of the Siljan Ring, an ancient meteorite impact site some 200 $\mathrm{km}$ northwest of Stockholm, in the hope of finding a large reservoir of natural gas. At 11:04 p.m. local time on 7 October, with the drill bit $2,833 \mathrm{~m}$ below the surface, oil began to wash up to the surface along with the usual mixture of rock debris and drilling fluid, says project manager Jack Kenney. Because no biological material should be present deep within a granite intrusion, the find would seem to support Gold's theory.

This latest claim to have struck oil is not the first to emerge from the project. Drilling on the present hole started only this year, but Dala Djupgas also claims to have pumped 80 barrels of oil in 1989 from a previous hole, drilled about $15 \mathrm{~km}$ away, near the crater's edge. That borehole, some 6,700 $\mathrm{m}$ deep, was abandoned last year, when the team ran into technical difficulties, Kenney says.

Dala Djupgas's first claim was dismissed by many petroleum geologists. Paul Philp, a University of Oklahoma geochemist who analysed samples of the 'black gunk' that Dala Djupgas extracted from the hole before pumping out the 80 barrels of oil, says that he could not distinguish between the samples from the hole and oil seeps found in shales near the surface in the Siljan area. Both, he says, contained similar 'biological marker' moleculescomplex molecules derived from biological material (cholestane, a derivative of cholesterol, is an example).

The obvious explanation, says Philp, was that oil had simply migrated down to the granite from sedimentary rocks near the surface.

Philp has declined to analyse any further samples from Siljan, arguing that his earlier findings were "taken out of context" by Gold and Dala Djupgas to support Gold's theory. But many geochemists suspect that the team was simply recovering the diesel oil drilling fluid that they had earlier pumped down the hole.

Kenney counters that extensive chemical analyses of the earlier samples show that they contain hydrocarbons other than those in the drilling fluid. And this time Kenney has a simpler argument to tackle the sceptics: the only drilling fluid that has so far been pumped down the second hole is, he says, fresh water.

"A lot of people are interested," says Chris Clayton from British Petroleum's Sunbury Research Centre in Middlesex. But he says that the industry will remain sceptical until Dala Djupgas provides samples for analysis. Kenney says that samples are being sent to a number of independent laboratories, but adds that the results will not be released until they have been reviewed by Dala Djupgas's eightmember scientific committee, which includes Gold. This may take several weeks, and even then, it seems unlikely that the samples will be made generally available, for commercial reasons.

Philp says that to be convinced that the new find does support Gold's ideas, he would want to see more geological data. If the rock surrounding the borehole is highly fractured (as it is likely to be, given the meteorite impact), he says, it is possible that the oil could have seeped into the granite from the surrounding shales. The Siljan Ring consists of a $40-\mathrm{km}$ diameter intrusion of granite, surrounded by sediments.

The Swedish drilling project began in 1986, funded largely by the state-owned Swedish electricity utility Vattenfall, after Gold had convinced the organization that the Siljan site could hold huge reserves of gas or oil. Sweden has little coal, gas or oil, and with its population strongly averse to nuclear power, it is anxious to find new energy sources. But Vattenfall eventually withdrew from the project last year, which forced the drilling company to attract private funding to begin drilling the second hole.

The new find comes at an opportune time for the company, which is currently in the middle of a share issue to raise more capital for the project. But Kenney rejects any suggestion that the timing of the announcement will benefit Dala Djupgas. Under Swedish law, he says, the price of shares in a new issue is fixed before the shares are released. Although Dala
Djupgas shares may now increase in value during secondary trading, the company will receive no more money for each share it sells. Nevertheless, last week's news does seem to have increased interest in the Dala Djupgas share offer. "Everyone in Sweden wants to buy shares," observes company president Lars Bahlberg.

\section{Peter Aldhous}

VIDEO TELECONFERENCES

\section{Long-distance hearing}

\section{Washington}

LAST week's congressional hearing on the future of the US national laboratories looked - with one exception - just like any other, with its parade of witnesses appearing before the House committee on Science, Space and Technology, reading their prepared statements and responding to questions from the committee members. The difference was that those witnesses were thousands of kilometres from Washington.

The hearing was the first of a series scheduled for this congressional session that will use 'video teleconferencing' to save witnesses from flying in and out of Washington - a journey that costs West Coast residents a day and a half or two days of work to attend a three-hour hearing.

"I can envision the day when quickturnaround hearings, multiple-point field hearings and regular interactions with witnesses testifying from abroad will all be done through video conference techniques," said committee chairman George Brown (Democrat, California) in his opening statement. "Getting to that point, however, will take some trial and error, such as what we will be experiencing this morning."

Actually, it was not as bad as Brown feared. Although the 15-frames-a-second technology (broadcast television uses 30 frames a second) made any sudden movements by the witnesses look jerky, that was a minor distraction. Audio problems blanked out a few words of testimony, but the sound was in general no worse than for most witnesses who appear in person. The least convenient part of the hearing was that only one channel was available, so that the committee had to hear first from one witness in Los Alamos, New Mexico, then switch to Livermore, California, to hear two more, and did not have the chance to go back and forth between the witnesses.

A number of federal agencies already use video teleconferencing to maintain contact among wide-flung outposts. The Department of Energy (DOE), for instance, uses it regularly to communicate with its national laboratories, and it was DOE's teleconferencing network that the committee borrowed for the hearing.

Robert Pool 